\title{
Suitability Evaluation for Spatial Expansion and Identification of Land Use Conflicts in Mountainous Country Villages and Towns: Take for Example Suining County
}

\author{
Wang Zhang, Jiadi Peng, Yu'an Liu, Xiaonan Cheng \\ College of Urban and Environmental Sciences, Hunan University of Technology, Zhuzhou, China
}

\author{
Email address: \\ 1191984429@qq.com (Jiadi Peng)
}

\section{To cite this article:}

Wang Zhang, Jiadi Peng, Yu'an Liu, Xiaonan Cheng. Suitability Evaluation for Spatial Expansion and Identification of Land Use Conflicts in Mountainous Country Villages and Towns: Take for Example Suining County. Earth Sciences. Vol. 10, No. 5, 2021, pp. $214-224$.

doi: $10.11648 /$ j.earth.20211005.13

Received: September 24, 2021; Accepted: October 11, 2021; Published: October 21, 2021

\begin{abstract}
Suining County of Shaoyang City, Hunan Province, was used as a suitability evaluation system from two aspects of natural and human factors including 12 indicators. The analytic hierarchy process and multi-factor weighted evaluation model were adopted to carry out the evaluation of the suitability of the spatial expansion of villages and towns for county-level. On this basis, the propensity intensity of three types of land use for villages and towns, agriculture, and ecology was calculated. Then, the high, middle and low grades were classified by the natural break point method, and the land use conflict recognition matrix was listed. Finally, the results of land use conflict identification were obtained. The results showed that: Suining County has significant differences in the suitability of spatial expansion of villages and towns, and the spatial distribution characteristics of different levels were quite different. The areas of the most suitable area, more suitable area, basic suitable area, less suitable area and unsuitable area for spatial expansion of villages and towns were respectively $183.67 \mathrm{~km}^{2}, 699.04 \mathrm{~km}^{2}, 1072.281 \mathrm{~km}^{2}$, $1006.79 \mathrm{~km}^{2}$ and $576.47 \mathrm{~km}^{2}$. The suitability of spatial expansion of each township was obviously different. The predominant land use areas of villages and towns were mainly distributed in Zhaishi Miao and Dong Township and Changpu Town in the south, and Shuikou Township and Jinwutang in the north Towns, etc. Dominant agricultural land areas were mainly distributed in the northeast of Tangjiafang, Huangtu Mine, Hongyan and other towns. The dominant ecological land area was relatively large, and the distribution was relatively scattered. The types of areas with obvious potential land use conflicts were the general conflict areas and intensified conflict areas, among which the general conflict areas were the largest, accounting for nearly half of the total area, and the intense conflict areas were the smallest. The areas of intense conflicts between villages and towns and agriculture, and the areas with intense conflicts between ecology and agriculture were all relatively small.
\end{abstract}

Keywords: Mountain, Spatial Expansion of Villages and Towns, Suitability Evaluation, Land Use Conflict, Suining County

\section{Introduction}

In recent years, research on the spatial expansion of regional land had become one of the hot issues that professional scholars in planning, geography, landscape, agriculture, forestry and environment at home and abroad. New evaluation models, analysis methods and research perspectives were emerged. Because developed countries have completed the process of urbanization, foreign research mainly focuses on the expansion of urban construction land suitability evaluation, including the site selection of urban infrastructure construction [1], the suitability evaluation of residential areas [2], and landscape ecological planning [3] etc. Many domestic scholars have also carried out a large number of studies on the suitability evaluation of urban construction land from different regions, different scales, and different methods. Studies have achieved certain results: from the perspective of the research area in China, it involves the southwest mountainous area [4], and the Xiangjiang new area in Hunan province [5], Karst area [6], Shenyang economic zone [7], the research scale is gradually reduced from the scale of cities and counties to industrial area, economic development zones, etc. From the perspective of research methods, Cai chunying [8] used GIS methods to carry out the evaluation of the suitability of construction land in 
Jiangdong New District, Haikou City; Yan Huiming [9] used two methods: the suitability index evaluation method and the short-board effect evaluation method to carry out a comparative study on the suitability evaluation methods for the construction and development of land resources in Fujian province; Jiang Xiaoli [10] took the "three generations" space as the perspective and combined the minimum cumulative resistance model with the slope direction variability and slope shape combination method to evaluate the suitability of construction land. There are few studies on the evaluation of the suitability of rural residential land use. Some scholars have studied the scale of counties, such as Dujiangyan city [11], Qixia city [12], Fang county [13], Cili county [14], etc. The rationality of the layout of rural residential areas has been usefully explored. In recent years, foreign scholars have made more comprehensive, in-depth and complete researches on conflicts in land use, mainly focusing on conflict sources [15], types [16], identification [17], evolution [18] and control [19], etc. At present, the main focus in China is on the types and identification of land use conflicts [20-22]. Throughout the domestic and foreign studies, there are more studies on the evaluation of land suitability in mountainous counties, but there is no research on the evaluation of suitability for spatial expansion of villages and towns; In addition, a comparison matrix of villages and towns, agricultural and ecological tendencies is constructed to identify potential land, The conflict areas used and the results of conflict identification are still rare.

In this study, Suining County, a typical mountainous area, was selected as the study area, and the evaluation index system was determined from a total of 12 index factors from natural and human factors. Comprehensive use of analytic hierarchy process, GIS spatial analysis, multi-factor weighted evaluation model and other methods to evaluate the suitability of the spatial expansion of its villages and towns; On this basis, the propensity intensity of the three types of land use for construction, agriculture, and ecology was calculated, and then divided into three grades of high, medium and low by using the natural breaking point method, and then the land use conflict identification matrix was listed, and finally the land use conflict identification results were obtained. In this way, the relationship between land development, utilization and protection in villages and towns was coordinated, and the application scenarios of conflict identification results were enriched, in order to provide theoretical guidance and technical support for the preparation of land and space planning of villages and towns, and promote High-Quality sustainable development in mountainous counties.

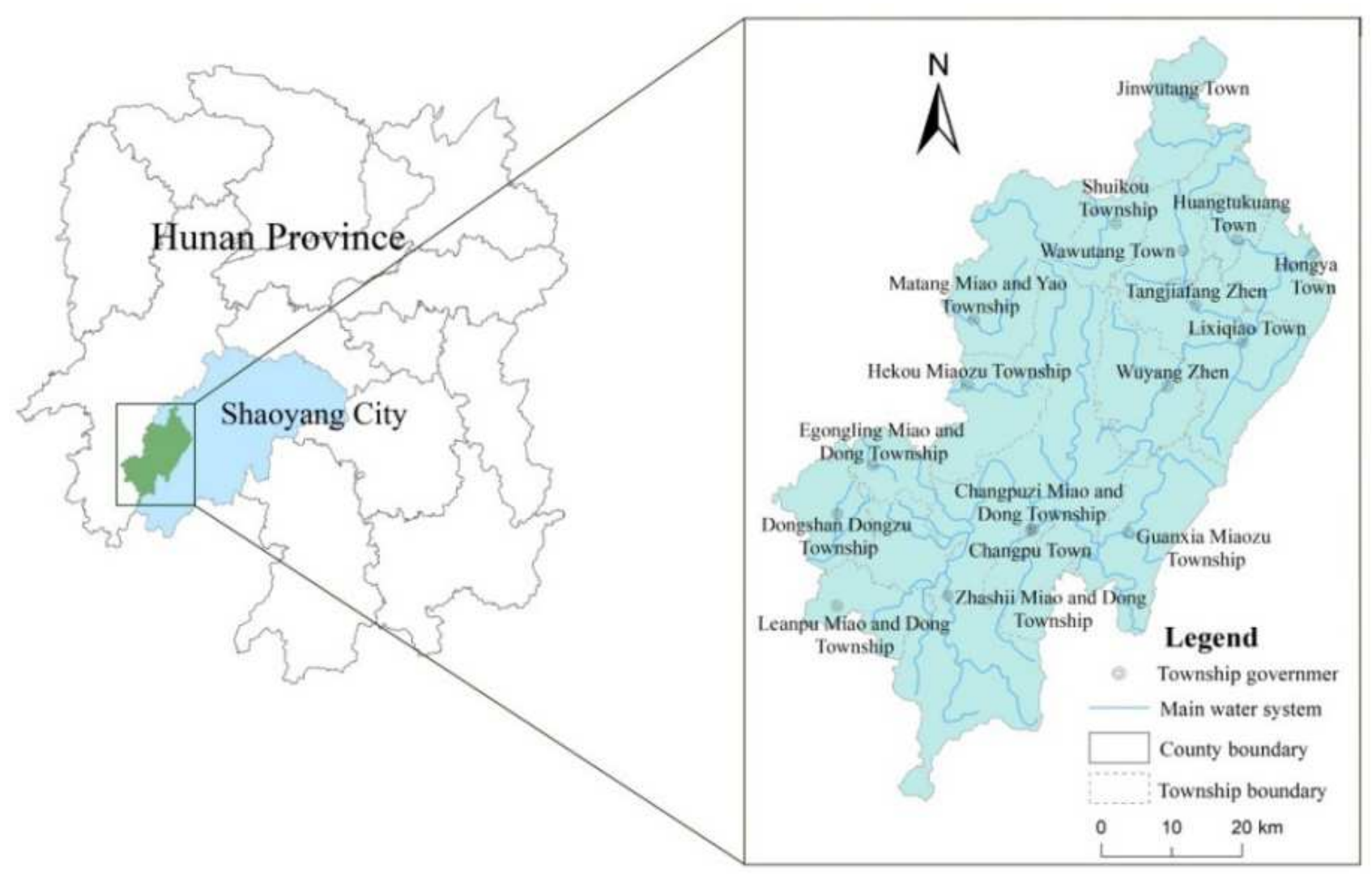

Figure 1. The scope of the administrative area of the study area.

\section{Overview of the Study Area}

Suining County (Figure 1), with geographic coordinates of $109^{\circ} 49^{\prime}-110^{\circ} 32^{\prime}$ east longitude and $26^{\circ} 16^{\prime}-27^{\circ} 8^{\prime}$ north latitude, is located on the western border of Shaoyang City, Hunan province. The county is dominated by mountains, and the total area of mountains and hills accounts for $96.5 \%$ of the total area. 
The southeast and north are mountainous areas. And the east, north and west are low mountainous areas. Wu river, a tributary of the Yuan river, enters from the east and traverses the central part; and the tributary of $\mathrm{Zi}$ river, Liao river, runs through the northeast. The climate is warm and humid, with four distinct seasons, abundant river water, more sunshine, less intense heat and less severe cold due to forest regulation, and belongs to a mid-subtropical monsoon humid climate with an average annual temperature of $16.7^{\circ} \mathrm{C}$ and an average annual rainfall of $1325 \mathrm{~mm}$. The county now has 17 townships under its jurisdiction (Shuikou, Zhaishi Miao and Dong, Changpuzi Miao and Dong, Dongshan Dong Township, Egongling Dong and Miao, Leanpu Miao and Dong, Guanxia Miao, Matang Miao and Yao, Hekou Miao, 9 in total township, Changpu, Wuyang, Lixiqiao, Hongyan, Tangjiafang, Jinwutang, Wawutang, Huangtukuang, 8 in total towns), 215 villages, 16 neighborhood committees. According to the data of the 7 th census in 2020, the permanent population was 290700, including 24 ethnic minorities such as Miao, Dong and Yao. The ethnic minority population accounted for $66.37 \%$ of total population. Within this county, Baomao Expressway, Dongxin Expressway connecting line, Wujing Expressway, and provincial highways S221 and S319 passed through the border.

\section{Data Sources and Research Methods}

\subsection{Data Sources}

The vector data of Suining county administrative districts, rivers, lakes, highways (national roads, provincial roads, county roads), scenic spots, etc. were from the National Basic Geographic Information Center (https://www.webmap.cn/); Digital Elevation (DEM) data was used The DEM collected by ALOS (2006) satellite phased array L-band synthetic aperture radar (PALSAR) came from the Tuxinyun GIS platform; the land use status data came from natural resources bureau of county; all the above data used ArcGIS 10.6 software for geography preprocessing such as registration, projection conversion and cropping. The spatial data involved in the operation was unified into a $12 \mathrm{~m} \times 12 \mathrm{~m}$ grid as the basic evaluation unit, and the coordinates were unified to the WGS_84_World_Mercator projection coordinate system.

\subsection{Research Methods}

\subsubsection{Select Evaluation Index}

The spatial expansion of villages and towns was usually affected by physical geography, social development, ecological environment, government policies, etc. Based on the literature on urban and rural construction land [23-25], combined with the regional characteristics of Suining county, the establishment of an evaluation index system was selected natural and human factors as an evaluation factor. Natural factors include elevation, slope, aspect, slope position, geological hazards, surface curvature, rivers and other data. Humanistic factors include traffic accessibility (distance from provincial, national and national roads, county and township roads and other transportation lines), important scenic spots, land use status, and basic farmland protection areas.

Elevation affects the level of spatial expansion and the sustainable development intensity, after the development of high-altitude mountainous areas, the environment is difficult to recover, and it will even have serious impacts on the surrounding low-altitude areas; slope restricts the difficulty of space expansion, and the greater the slope of the project, the greater the amount, and even damage the geological environment and affect the safety of residence; the aspect affects the direction of space expansion and the layout of the building, According to relevant literature, the aspect is divided into flat land/south slope $\left(-1^{\circ}\right)$, southeast slope/ Southwest slope $\left[157.5^{\circ}, 247.5^{\circ}\right)$, east slope/west slope $\left[247.5^{\circ}, 292.5^{\circ}\right)$ or $\left[112.5^{\circ}, 157.5^{\circ}\right)$, northeast slope/northwest slope $\left[67.5^{\circ}, 112.5^{\circ}\right)$ or $\left[292.5^{\circ}, 337.5^{\circ}\right)$, North Slope $\left[0^{\circ}, 67.5^{\circ}\right)$ or $\left[337.5^{\circ} 360^{\circ}\right)$ and other 5 slope directions; the slope position affects the difficulty of construction projects. The higher the slope, the greater the difficulty of construction and the more serious the damage to the geological environment; Geological disasters in the process of spatial expansion will not only increase engineering costs, but also cause secondary geological disasters; rivers and lakes (reservoirs) are not only important water sources, but also ecological corridors and landscape corridors, which are important ecological factors; Roads, railways and other traffic along the roads are not only attractive to the expansion of villages and towns, but also have greater restrictions on construction land; the current status of land use reflects the difficulty of in-situ reconstruction in a region [26], and the basic farmland protection area shall be permanently and strictly protected, and non-national major construction projects shall not be developed and constructed.

\subsubsection{Establishment of an Evaluation Model}

In this paper, a multi-factor weighted evaluation model was used to evaluate the suitability of the study area for spatial expansion of villages and towns. The process was as follows: according to the selected evaluation index, assign 5 as the most suitable area, assign 4 as the more suitable area, and assign 3 as the basic suitable area, assign 2 as the less suitable zone, and assign 1 as the grade division of the unsuitable zone (Table 2). The nature of the evaluation index was divided into elastic evaluation index and rigid evaluation index. The rigid evaluation index refers to the area where construction was prohibited and cannot be used as a candidate area for construction land, such as the basic farmland protection area. The elasticity evaluation index was uniformly quantified according to the index level, the attribute value of the index was determined, and the data was rasterized with ArcGIS 10.6 to form a grid distribution map of each index. Then use the expert scoring method to compare the two elastic indicators, and use the analytic hierarchy process to determine the weight of each indicator. Finally, the raster calculator was used to superimpose the grid distribution maps of each indicator, and the grades are divided and the areas that are forbidden to be constructed are deducted.

The model evaluation formula is:

$$
P_{j}=\sum_{i=1}^{n} F_{j, i}(g, w)
$$

In the formula, $P$ is the total score, $\mathrm{j}$ is the $\mathrm{j}$-th evaluation 
unit; $\mathrm{i}$ is the $\mathrm{i}$-th index; $\mathrm{n}$ is the total number of indexes; $\mathrm{g}$ is the index score value; $\mathrm{w}$ is the index weight.

Table 1. Evaluation index system and classification of suitability for spatial expansion of villages and towns.

\begin{tabular}{|c|c|c|c|c|c|c|c|c|c|}
\hline \multirow{3}{*}{$\begin{array}{l}\text { Target } \\
\text { Floor }\end{array}$} & \multirow{3}{*}{$\begin{array}{l}\text { Factor } \\
\text { layer }\end{array}$} & \multirow{3}{*}{ Index layer } & \multirow{3}{*}{ Weights } & \multicolumn{5}{|l|}{ Grading index } & \multirow{3}{*}{$\begin{array}{l}\text { index } \\
\text { nature }\end{array}$} \\
\hline & & & & $\begin{array}{l}\text { Most } \\
\text { suitable zone }\end{array}$ & $\begin{array}{l}\text { More suitable } \\
\text { area }\end{array}$ & $\begin{array}{l}\text { Basically } \\
\text { suitable area }\end{array}$ & $\begin{array}{l}\text { Less suitable } \\
\text { area }\end{array}$ & $\begin{array}{l}\text { Unsuitable } \\
\text { area }\end{array}$ & \\
\hline & & & & $\begin{array}{l}\text { Suitability } \\
\text { value }=5\end{array}$ & $\begin{array}{l}\begin{array}{l}\text { Suitability } \\
\text { value }=4\end{array} \\
\end{array}$ & $\begin{array}{l}\text { Suitability } \\
\text { value }=3\end{array}$ & $\begin{array}{l}\text { Suitability } \\
\text { value }=2\end{array}$ & $\begin{array}{l}\text { Suitability } \\
\text { value }=1\end{array}$ & \\
\hline \multirow{12}{*}{$\begin{array}{l}\text { Suitable for } \\
\text { expansion of } \\
\text { villages and } \\
\text { towns should } \\
\text { sex } \\
\text { Comment } \\
\text { price }\end{array}$} & \multirow{12}{*}{$\begin{array}{l}\text { Human } \\
\text { factors }\end{array}$} & Elevation $(\mathrm{m})$ & 0.15 & $194-485$ & $485-648$ & $648-843$ & $843-1094$ & $\geq 1094$ & elasticity \\
\hline & & Slope $\left(^{\circ}\right)$ & 0.08 & $\leq 10$ & $10-18$ & $18-26$ & $26-34$ & $\geq 34$ & elasticity \\
\hline & & Aspect & 0.05 & $\begin{array}{l}\text { Flat land/south } \\
\text { slope }\end{array}$ & $\begin{array}{l}\text { Southeast Slope/ } \\
\text { Southwest slope }\end{array}$ & $\begin{array}{l}\text { East slope/West } \\
\text { slope }\end{array}$ & $\begin{array}{l}\text { Northeast Slope/ } \\
\text { Northwest slope }\end{array}$ & North slope & elasticity \\
\hline & & Slope position & 0.08 & Downhill & / & Middle slope & / & Uphill & elasticity \\
\hline & & Surface curvature & 0.04 & $-1.3-1.3$ & $\begin{array}{l}-2.6-1.3 \text { or } \\
1.3-2.6\end{array}$ & $\begin{array}{l}-4.5-2.6 \text { or } \\
2.6-4.5\end{array}$ & $-7-4.5$ or 4.57 & $\leq-7$ or $\geq 7$ & elasticity \\
\hline & & Geological disaster & 0.12 & Less prone area & Low-prone zone & $\begin{array}{l}\text { Central Prone } \\
\text { Area }\end{array}$ & l & $\begin{array}{l}\text { High Prone } \\
\text { Area }\end{array}$ & elasticity \\
\hline & & $\begin{array}{l}\text { Distance from the } \\
\text { river }(m)\end{array}$ & 0.08 & $\geq 2000$ & $1500-2000$ & $1000-1500$ & $500-1000$ & $\leq 500$ & elasticity \\
\hline & & $\begin{array}{l}\text { Distance to county } \\
\text { (township) road (m) }\end{array}$ & 0.03 & $\leq 500$ & $500-1000$ & $1000-1500$ & $1500-2000$ & $\geq 2000$ & elasticity \\
\hline & & $\begin{array}{l}\text { Distance to national } \\
\text { (provincial) road (m) }\end{array}$ & 0.04 & $\leq 1000$ & $1000-1500$ & $1500-2000$ & $2000-2500$ & $\geq 2500$ & elasticity \\
\hline & & $\begin{array}{l}\text { Distance to important } \\
\text { sights }(\mathrm{m})\end{array}$ & 0.05 & $\geq 2000$ & $1500-2000$ & $1000-1500$ & $500-1000$ & $\leq 500$ & elasticity \\
\hline & & Land use status & 0.15 & $\begin{array}{l}\text { Construction } \\
\text { land }\end{array}$ & $\begin{array}{l}\text { Industrial and } \\
\text { mining land, } \\
\text { bare land }\end{array}$ & $\begin{array}{l}\text { Gardens, ponds, } \\
\text { grasslands, other } \\
\text { land }\end{array}$ & $\begin{array}{l}\text { Rivers (lakes, } \\
\text { reservoirs) }\end{array}$ & $\begin{array}{l}\text { Cultivated } \\
\text { land, } \\
\text { woodland }\end{array}$ & elasticity \\
\hline & & $\begin{array}{l}\text { Basic Farmland } \\
\text { Reserve }\end{array}$ & 0.13 & No & No & No & No & Yes & Rigidity \\
\hline
\end{tabular}

\subsubsection{Calculate the Strength of Land Preference}

Based on the LUCIS suitability evaluation of Carr MH et al. [27-29], for the three major spaces of construction, agriculture, and ecology, this paper used the evaluation indicators and corresponding weights for the expansion of villages and towns in Table 1 to reclassify: The distance to the provincial national roads, county and township roads and other transportation lines, the distance to the river, and the construction land, industrial and mining land, and bare land in the current land were used as indicators of the suitability of the construction space; the basic farmland protection area and the dry land in the current land paddy fields, etc., were used as indicators of the suitability of agricultural space; elevation, slope, aspect, slope position, geological disasters, surface curvature, important scenic spots, and woodland and grassland in the current land were used as indicators of the suitability of ecological spaces. Thus, a multi-objective orientation evaluation model was constructed to calculate the suitability of the three major spaces in each evaluation unit. Then use the weighted index and the model to calculate the land use tendency intensity of each grid.
The formula is:

$$
I=\sum W_{i 1} \cdot W_{i 2} \cdot W_{i 3} \cdot V_{i}
$$

In the formula: $\mathrm{I}$ is the strength of a certain type of spatial land use tendency. The larger the value of I, the higher the specific spatial land use tendency; $\mathrm{W}_{\mathrm{i} 1}, \mathrm{~W}_{\mathrm{i} 2}, \mathrm{~W}_{\mathrm{i} 3}$ are the weights of a certain spatial layer, factor layer, and index layer, respectively, and $\mathrm{V}_{\mathrm{i}}$ is the suitability score value of the $\mathrm{i}$-th grading index.

\subsubsection{Compile a Land Use Conflict Recognition Matrix}

The natural breaks method was used to classify the propensity intensity of the three major spaces for construction, agriculture, and ecology, which were divided into three levels: high, medium, and low. Permutations and combinations were based on the different inclination intensity levels of the three major spaces, which were used as a recognition matrix to determine the types of potential land-use conflicts in each evaluation unit, and made a classification table of potential land-use conflict areas (Table 2).

Table 2. Classification table of potential land use conflict zones.

\begin{tabular}{|c|c|c|c|c|}
\hline \multirow{2}{*}{$\begin{array}{l}\text { Potential land use conflict } \\
\text { type area (Class } 1)\end{array}$} & \multirow{2}{*}{ Potential land use conflict type area (Class 2) } & \multicolumn{3}{|c|}{ Site preference strength combination } \\
\hline & & Construction & Agriculture & Ecology \\
\hline \multirow{5}{*}{ Advantageous area (Y) } & \multirow[b]{2}{*}{ Advantageous area of construction land (Y1) } & high & middle & middle \\
\hline & & high & low & low \\
\hline & \multirow{2}{*}{ Advantageous area of agricultural land (Y2) } & low & high & low \\
\hline & & low & middle & low \\
\hline & Advantageous area of ecological land (Y3) & low & low & high \\
\hline
\end{tabular}




\begin{tabular}{|c|c|c|c|c|}
\hline \multirow{2}{*}{$\begin{array}{l}\text { Potential land use conflict } \\
\text { type area (Class 1) }\end{array}$} & \multirow{2}{*}{ Potential land use conflict type area (Class 2) } & \multicolumn{3}{|c|}{ Site preference strength combination } \\
\hline & & Construction & Agriculture & Ecology \\
\hline \multirow{8}{*}{ Zone of intense conflict $(\mathrm{J})$} & \multirow{2}{*}{ Intense conflict zone between construction and agriculture (J1) } & high & high & middle \\
\hline & & high & high & low \\
\hline & \multirow{2}{*}{ Intense conflict zone between construction and ecology ( $\mathrm{J} 2)$} & high & middle & high \\
\hline & & high & low & high \\
\hline & \multirow{2}{*}{ Intense conflict zone between agriculture and ecology (J3) } & low & high & high \\
\hline & & middle & high & high \\
\hline & \multirow[t]{2}{*}{ Three types of land use intense conflict zone (J4) } & high & high & high \\
\hline & & middle & middle & low \\
\hline \multirow{10}{*}{ General conflict zone (B) } & \multirow{3}{*}{ General conflict zone between construction and agriculture (B1) } & high & middle & low \\
\hline & & middle & high & low \\
\hline & & middle & low & middle \\
\hline & \multirow[t]{3}{*}{ General conflict zone between construction and ecology (B2) } & middle & low & high \\
\hline & & high & low & middle \\
\hline & & low & middle & middle \\
\hline & \multirow[t]{2}{*}{ General conflict zone between agriculture and ecology (B3) } & low & middle & high \\
\hline & & low & high & middle \\
\hline & Three types of land use general conflict zone (B4) & middle & middle & middle \\
\hline & Weak conflict zone (W1) & middle & middle & high \\
\hline
\end{tabular}

\section{Results and Analysis}

Based on the index weights and their classification assignments in the suitability evaluation index system of Suining County, the single factor was evaluated and analyzed through ArcGIS, and the formula (1) was used for comprehensive evaluation, the result value was 1.29-4.36, then the study area was divided into the most suitable area, more suitable area, basic suitable area, less suitable area and unsuitable area by using the natural break point method. According to formula (2) calculation of the construction, agriculture, ecological land propensity intensity 3 large space, using the identification matrix built, ArcGIS 10.6 land space of three tendencies intensity overlay analysis means, get Suining county land use conflicts to identify potential outcomes (Figure 5, Table 5).
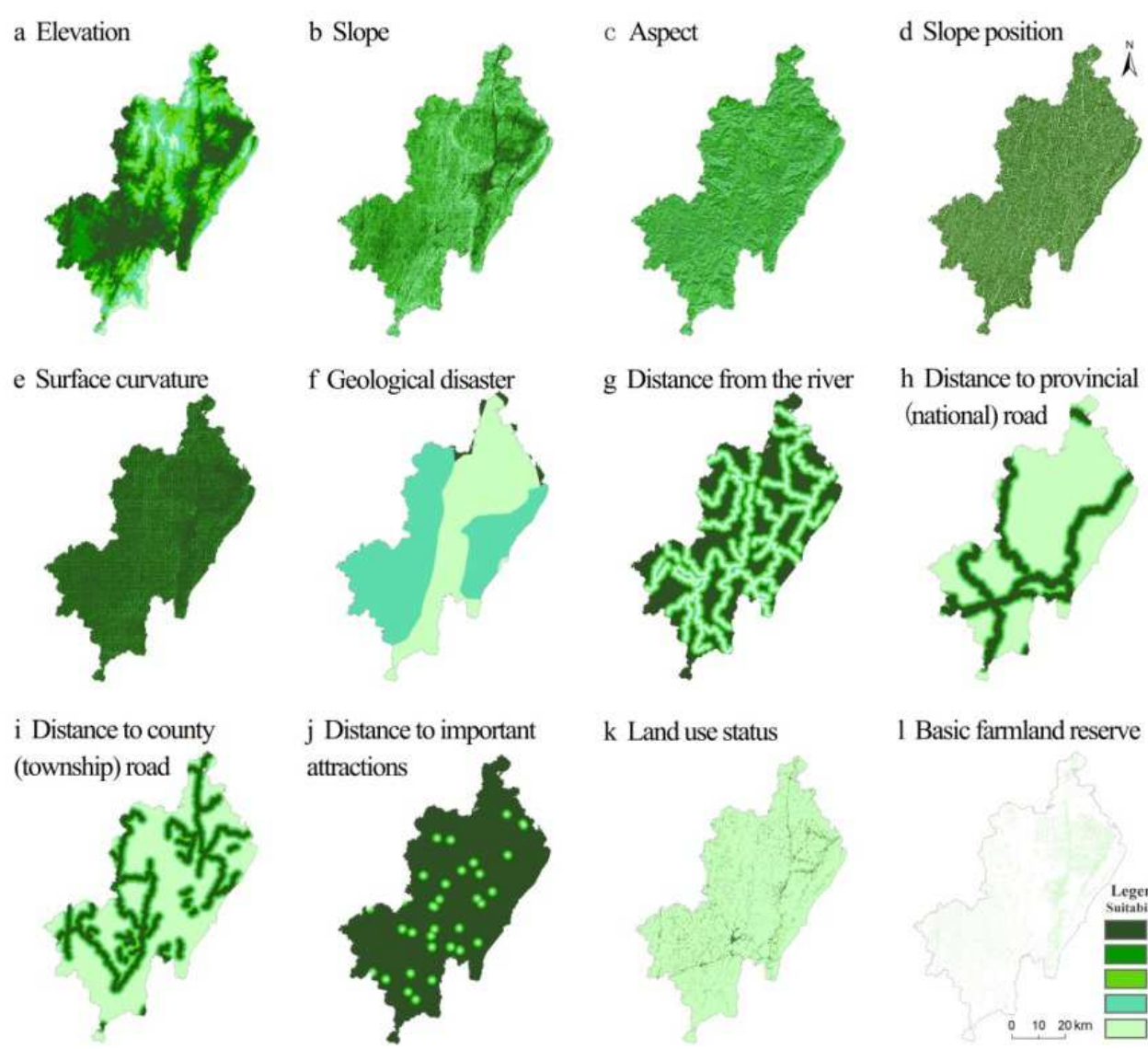

k Land use status

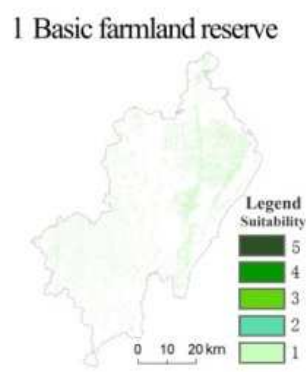

Figure 2. Single-factor evaluation results of the suitability of spatial expansion of villages and towns in Suining County. 


\subsection{Analysis of Single Factor Evaluation Results}

Carry on spatial analysis to 12 evaluation factors, with ArcGIS 10.6, the results are shown in Figure 2 and Table 3.

The lowest elevation of Suining county is $194 \mathrm{~m}$, the elevation is between $194-485 \mathrm{~m}$, and the area is $1114.25 \mathrm{~km}^{2}$, accounting for $30.52 \%$ of the study area, and about $69.48 \%$ of the area is above $485 \mathrm{~m}$, the overall elevation of Suining County is relatively high and the mountain area is relatively high, it is difficult to construct cities and towns, so it is necessary to reasonably arrange the expansion of villages and towns (Figure 2a); Suining County covers an area of $658.57 \mathrm{~km}^{2}$ with a slope of less than $10^{\circ}$, accounting for $18.04 \%$, it is mainly distributed on both sides of the northeast basin, and the area greater than $10^{\circ}$ accounts for $81.96 \%$ are distributed in the southwestern region (Figure 2b); Suining county's southeast slope/southwest slope, east slope/west slope, and northeast slope/northwest slope account for $24.64 \%, 24.95 \%$, and $23.41 \%$, respectively (Figure $2 \mathrm{c}$ ); The slope position of Suining county is divided into uphill, middle broken, and downhill, accounting for $19.62 \%$, $53.79 \%$, and $23.58 \%$ respectively (Figure 2d); Suining County has an area of $2375.35 \mathrm{~km}^{2}$ with surface curvature between-1.3 and 1.3, Accounting for $70.56 \%$, reflecting the small surface undulations in the overall evaluation unit (Figure 2e); Suining county's non-, low, medium, and high-prone areas accounted for $1.73 \%, 0.01 \%, 54.67 \%$, and 43.58 (Figure 2f); Rivers in Suining county are mainly distributed in the southeast, with an area of $1,237.95 \mathrm{~km}^{2}$ within $500 \mathrm{~m}$ of the river, accounting for $33.92 \%$ of the total area, which is more restrictive to spatial expansion of the towns in the east (Figure 2g). From the perspective of natural factors, the overall elevation of Suining county is relatively high, the slope is relatively large, and the terrain is continuously undulating, which restricts the expansion of the space of villages and towns.

Suining county had 2 highways, 2 provincial highways and 5 national highways passing through (Figure 2h), county (township) roads were dense but unevenly distributed (Figure 2i), In general, traffic arteries were mainly distributed in the southwestern region, and there was only one provincial highway in the northeast, which was not conducive to the expansion of the space of villages and towns; Suining county had many important scenic spots or nature reserves, which had a greater impact on the spatial expansion of villages and towns. The area outside the 2000 $\mathrm{km}$ range of important scenic spots was $3178.10 \mathrm{~km}^{2}$, accounting for $87.07 \%$ (Figure $2 \mathrm{j}$ ); The construction land in Suining county was mainly distributed in the east and southwest, with a total area of $102.10 \mathrm{~km}^{2}$, accounting for $2.80 \%$, and an area of arable and woodland of $3321.10 \mathrm{~km}^{2}$, accounting for $90.97 \%$, which restricted the expansion of villages and towns (Figure 2k); The basic farmland protection areas in Suining county were scattered, with a total area of $369.96 \mathrm{~km}^{2}$, which had a greater impact on development and construction (Figure 21). The impact of humanistic factors on the spatial expansion of villages and towns in Suining county was mainly due to the large area of agricultural land. The development of basic farmland protection areas was prohibited during the development process, which limits the direction and scope of the spatial expansion of villages and towns to a certain extent.

Table 3. Single-factor evaluation of suitability for spatial expansion of villages and towns in Suining County.

\begin{tabular}{|c|c|c|c|c|c|c|c|c|c|c|}
\hline \multirow[b]{2}{*}{ Evaluation factor } & \multicolumn{2}{|c|}{ Most suitable area } & \multicolumn{2}{|c|}{ More suitable area } & \multicolumn{2}{|c|}{ Basically suitable area } & \multicolumn{2}{|c|}{ Less suitable area } & \multicolumn{2}{|c|}{ Unsuitable area } \\
\hline & $\begin{array}{l}\text { Area } \\
/ \mathbf{k m}^{2}\end{array}$ & $\begin{array}{l}\text { Percentage } \\
1 \%\end{array}$ & $\begin{array}{l}\text { Area } \\
/ \mathbf{k m}^{2}\end{array}$ & $\begin{array}{l}\text { Percentage } \\
1 \%\end{array}$ & Area $/ \mathbf{k m}^{2}$ & $\begin{array}{l}\text { Percentage } \\
/ \%\end{array}$ & $\begin{array}{l}\text { Area } \\
/ \mathbf{k m}^{2}\end{array}$ & $\begin{array}{l}\text { Percentage } \\
1 \%\end{array}$ & $\begin{array}{l}\text { Area } \\
/ \mathbf{k m}^{2}\end{array}$ & $\begin{array}{l}\text { Percentage } \\
/ \%\end{array}$ \\
\hline Elevation (m) & 1114.25 & 30.53 & 1040.14 & 28.50 & 762.34 & 19.90 & 494.75 & 13.55 & 170.81 & 4.68 \\
\hline Slope $\left(^{\circ}\right)$ & 658.71 & 18.50 & 967.78 & 21.18 & 1003.90 & 28.20 & 673.80 & 18.93 & 236.30 & 6.64 \\
\hline Aspect & 658.58 & 18.04 & 899.43 & 24.64 & 910.53 & 24.95 & 854.29 & 23.40 & 217.51 & 5.96 \\
\hline Surface curvature & 2575.35 & 70.56 & 693.01 & 18.97 & 221.46 & 6.07 & 51.46 & 1.41 & 5.02 & 0.14 \\
\hline Geological disaster & 63.18 & 1.73 & 0.24 & 0.01 & 1996.11 & 54.67 & l & I & 1591.15 & 43.58 \\
\hline Distance to the river $(\mathrm{m})$ & 1237.95 & 33.92 & 452.13 & 12.39 & 528.54 & 14.48 & 590.45 & 16.18 & 737.21 & 20.20 \\
\hline Distance to county (township) road (m) & 542.20 & 14.85 & 442.21 & 12.12 & 392.54 & 10.75 & 375.43 & 10.29 & 1793.92 & 49.15 \\
\hline Distance to national (provincial) road (m) & 590.77 & 16.19 & 224.28 & 6.14 & 217.64 & 5.96 & 205.44 & 5.63 & 2308.17 & 63.24 \\
\hline Distance to important sights (m) & 3178.00 & 87.07 & 154.96 & 4.24 & 122.72 & 3.36 & 61.78 & 1.69 & 28.83 & 0.79 \\
\hline Land use status & 102.10 & 2.80 & 2.25 & 0.06 & 91.41 & 2.50 & 29.54 & 0.81 & 3321.00 & 90.97 \\
\hline Basic Farmland Reserve & 1 & 1 & 1 & 1 & l & 1 & 1 & 1 & 369.96 & 10.14 \\
\hline
\end{tabular}

\subsection{Comprehensive Evaluation Result Analysis}

ArcGIS 10.6 by processing and other software, get Suining county town space expansion comprehensive evaluation of suitability (Figure 3), and count the Suining county township spatial expansion suitability evaluation results (Table 4).

The comprehensive evaluation of the spatial expansion of villages and towns in Suining county was: the areas of the most suitable area, more suitable area, basic suitable area, less suitable area and unsuitable area were $183.67 \mathrm{~km}^{2}, 699.04 \mathrm{~km}^{2}$, $1072.28 \mathrm{~km}^{2}, 1006.79 \mathrm{~km}^{2}$ and $576.47 \mathrm{~km}^{2}$. Among them, the basic suitable area was the largest, accounting for $29.37 \%$ of the study area; the most suitable area was the smallest, accounting for $5.03 \%$ of the study area; the more suitable area, the less suitable area, and the unsuitable area account for $19.15 \%, 27.58 \%, 15.79 \%$. 
Table 4. Suitability analysis of the spatial expansion of each township in Suining county.

\begin{tabular}{|c|c|c|c|c|c|c|c|c|c|c|}
\hline \multirow[b]{2}{*}{ Township } & \multicolumn{2}{|c|}{ Most suitable area } & \multicolumn{2}{|c|}{ More suitable area } & \multicolumn{2}{|c|}{ Basically suitable area } & \multicolumn{2}{|c|}{ Less suitable area } & \multicolumn{2}{|c|}{ Unsuitable area } \\
\hline & $\begin{array}{l}\text { Area } \\
/ \mathbf{k m}^{2} \\
\end{array}$ & $\begin{array}{l}\text { Percentage } \\
/ \%\end{array}$ & $\begin{array}{l}\text { Area } \\
/ \mathbf{k m}^{2} \\
\end{array}$ & $\begin{array}{l}\text { Percentage } \\
/ \%\end{array}$ & Area $/ \mathbf{k m}^{2}$ & $\begin{array}{l}\text { Percentage } \\
/ \%\end{array}$ & $\begin{array}{l}\text { Area } \\
/ \mathbf{k m}^{2} \\
\end{array}$ & $\begin{array}{l}\text { Percentage } \\
/ \%\end{array}$ & $\begin{array}{l}\text { Area } \\
/ \mathbf{k m}^{2} \\
\end{array}$ & $\begin{array}{l}\text { Percentage } \\
/ \%\end{array}$ \\
\hline Changpuzi Miao and Dong Township & 25.54 & 3.69 & 104.51 & 15.09 & 194.69 & 28.12 & 222.25 & 32.10 & 145.00 & 20.94 \\
\hline Changpu Town & 3.81 & 24.2 & 3.43 & 21.8 & 6.29 & 39.95 & 2.15 & 13.65 & 0.06 & 0.04 \\
\hline Zhaishi Miao and Dong Township & 24.89 & 4.81 & 102.15 & 19.73 & 134.08 & 25.90 & 119.22 & 23.03 & 136.02 & 26.28 \\
\hline Wuyang Zhen & 8.57 & 3.81 & 42.24 & 18.76 & 64.12 & 28.47 & 62.06 & 27.55 & 48.22 & 21.41 \\
\hline Wawutang Town & 4.89 & 2.25 & 10.67 & 4.92 & 44.91 & 20.70 & 101.04 & 46.57 & 54.91 & 25.31 \\
\hline Shuikou Township & 1.48 & 1.33 & 4.60 & 4.15 & 16.54 & 14.91 & 47.61 & 42.93 & 40.54 & 36.55 \\
\hline Matang Miao and Yao Township & 20.54 & 6.53 & 66.77 & 21.31 & 80.82 & 25.80 & 101.08 & 32.27 & 43.26 & 13.81 \\
\hline Lixiqiao Town & 7.85 & 3.48 & 35.64 & 15.79 & 81.40 & 36.08 & 73.19 & 32.44 & 27.03 & 11.98 \\
\hline Leanpu Miao and Dong Township & 12.17 & 9.24 & 54.12 & 41.08 & 53.29 & 40.45 & 11.27 & 8.56 & 0.34 & 0.26 \\
\hline Jinwutang Town & 6.41 & 4.86 & 20.22 & 15.35 & 39.90 & 30.29 & 59.49 & 45.16 & 38.03 & 28.87 \\
\hline Huangtukuang Town & 3.16 & 4.56 & 8.17 & 11.79 & 23.49 & 33.91 & 24.01 & 34.67 & 10.43 & 15.06 \\
\hline Hongyan Town & 11.51 & 7.34 & 34.04 & 21.71 & 61.47 & 39.22 & 36.27 & 23.14 & 12.75 & 8.13 \\
\hline Guanxia Miaozu Township & 14.86 & 5.48 & 73.63 & 27.16 & 93.24 & 34.39 & 67.23 & 24.80 & 21.07 & 7.77 \\
\hline Egongling Miao and Dong Township & 7.73 & 8.48 & 34.65 & 37.98 & 33.79 & 37.04 & 14.16 & 15.53 & 0.61 & 0.67 \\
\hline Dongshan Dongzu Township & 7.22 & 4.96 & 46.68 & 32.06 & 69.01 & 47.40 & 21.49 & 14.76 & 0.59 & 0.40 \\
\hline Total & 184.41 & 109.71 & 719.32 & 357.2 & 1108.44 & 556.69 & 1038.94 & 455.82 & 591.29 & 226.57 \\
\hline
\end{tabular}

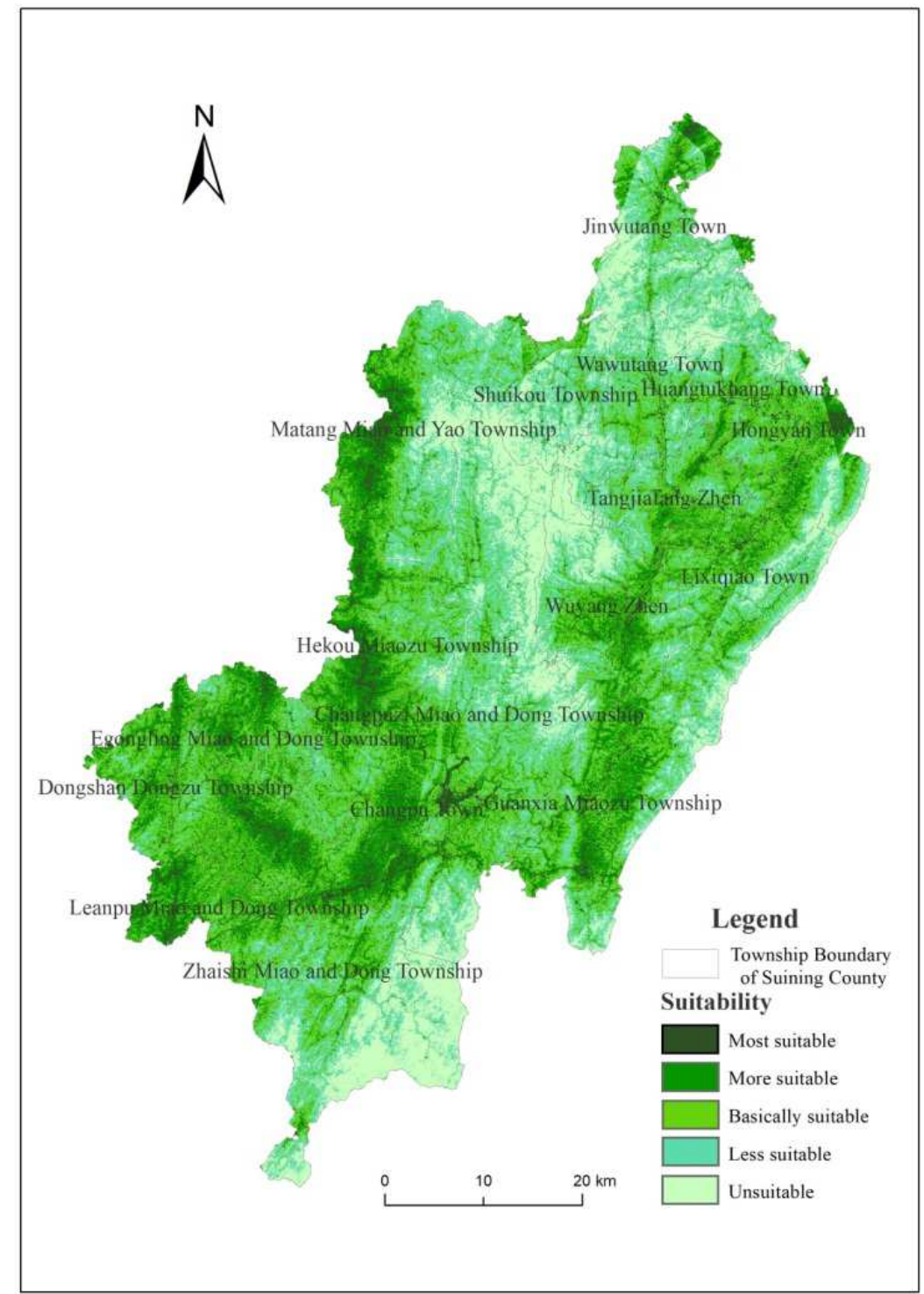

Figure 3. Comprehensive evaluation results of the suitability for spatial expansion of villages and towns in Suining county. 
The results of the suitability of the spatial expansion of the townships in Suining county were as follows: Changpuzi Miao and Dong Township has the largest unsuitable area of $222.25 \mathrm{~km}^{2}$, accounting for $32.10 \%$ of the town's area, and the smallest area of the most suitable district was $25.54 \mathrm{~km}^{2}$, accounting for $3.69 \%$ of the town's area; The most suitable area of Changpu town was $6.29 \mathrm{~km}^{2}$, accounting for $39.95 \%$ of the town's area, and the smallest unsuitable area was $0.06 \mathrm{~km}^{2}$, accounting for $0.04 \%$ of the town's area; the most unsuitable area of Zhaishi Miao and Dong township was $136.02 \mathrm{~km}^{2}$, accounting for $26.28 \%$ of the town's area, the smallest area of the most suitable area was $24.89 \mathrm{~km}^{2}$, accounting for $2.25 \%$ of the town's area; Wuyang town's basic suitable area was the largest area of $64.12 \mathrm{~km}^{2}$, accounting for $28.47 \%$ of the town's area, the most suitable area The smallest area was $8.57 \mathrm{~km}^{2}$, accounting for $3.81 \%$ of the town's area; the most suitable area of Wawutang town was $101.04 \mathrm{~km}^{2}$, accounting for $46.57 \%$ of the town's area, and the most suitable area was the smallest being $4.89 \mathrm{~km}^{2}$ accounting for $2.25 \%$ of the town's area; The most suitable area in Tangjiafang town was $47.47 \mathrm{~km}^{2}$, accounting for $38.00 \%$ of the town's area, the smallest unsuitable area was $5.44 \mathrm{~km}^{2}$, accounting for $4.35 \%$ of the town's area; the less suitable area in Shuikou township was the largest area being $47.61 \mathrm{~km}^{2}$, accounting for $42.93 \%$ of the area of the town, the smallest area of the most suitable area was $1.48 \mathrm{~km}^{2}$, accounting for $1.33 \%$ of the area of the town; the most suitable area of Matang Miao and Yao township was 101.08 $\mathrm{km}^{2}$, accounting for $32.27 \%$ of the area of the town, the area of unsuitable area The smallest area was $20.54 \mathrm{~km}^{2}$, accounting for $6.53 \%$ of the town's area; the most suitable area in Lixiqiao town was $81.40 \mathrm{~km}^{2}$, accounting for $36.08 \%$ of the town's area, and the smallest area was $7.85 \mathrm{~km}^{2}$, accounting for $3.48 \%$ of the town's area; The most suitable area in Leanpu Miao and Dong township was $54.2 \mathrm{~km}^{2}$, accounting for $48.01 \%$ of the town's area, the smallest unsuitable area was $0.34 \mathrm{~km}^{2}$, accounting for $0.26 \%$ of the town's area; the basic suitable area in Jinwutang town was the largest at $59.49 \mathrm{~km}^{2}$, Accounting for $45.16 \%$ of the area of the town, the smallest area of the most suitable area was $6.41 \mathrm{~km}^{2}$, accounting for $4.86 \%$ of the area of the town; the area of the basic suitable area of the Huangtukuang town was the largest at $24.01 \mathrm{~km}^{2}$, accounting for $34.67 \%$ of the area of the town, the most suitable area The smallest area was $3.16 \mathrm{~km}^{2}$, accounting for $4.56 \%$ of the town's area; the most suitable area in Hongyan town was $61.47 \mathrm{~km}^{2}$, accounting for $39.22 \%$ of the town's area, and the smallest unsuitable area was $11.51 \mathrm{~km}^{2}$, accounting for $7.34 \%$ of the town's area; The most suitable area in Hekou Miao township was $63.93 \mathrm{~km}^{2}$, accounting for $36.06 \%$ of the town's area, and the smallest unsuitable area was $3.56 \mathrm{~km}^{2}$, accounting for $2.06 \%$ of the town's area; Guanxia Miao township's basic suitable area was the largest area of $93.24 \mathrm{~km}^{2}$, it accounts for $34.39 \%$ of the town's area, and the smallest unsuitable area was 14.86 $\mathrm{km}^{2}$, which accounts for $5.48 \%$; the most suitable area of
Egongling Miao and Dong township was $34.65 \mathrm{~km}^{2}$, accounting for $37.98 \%$ of the town's area, and the smallest unsuitable area was $0.61 \mathrm{~km}^{2}$, accounting for $0.67 \%$ of the town's area; Dongshan Dong township's basic suitable area was the largest $46.68 \mathrm{~km}^{2}$, accounting for $32.06 \%$ of the town's area, and the smallest unsuitable area was $0.59 \mathrm{~km}^{2}$, accounting for $0.40 \%$ of the town's area.

It can be seen from Figure 3 that the suitability of spatial expansion of villages and towns in Suining county has significant spatial differences, and the spatial distribution characteristics of different levels were quite different. The most suitable area was small and scattered, mainly in Changpu town, Hekou Miao township, Leanpu Miao and Dong township, etc. Because these areas were low in elevation and relatively flat, the existing urban built-up areas were concentrated and the transportation was convenient., Economically developed and less in ecological protection areas, suitable for construction land development; more suitable areas and basic suitable areas were more concentrated, such as Dongshan Dong township, Leanpu Miao and Dong township, and Egongling Miao and Dong township areas, which were more suitable for development, during the construction of villages and towns in areas and basically suitable areas, over-development should be avoided according to actual conditions and ecological protection requirements; less suitable areas were large in area and relatively concentrated, mainly distributed in the central, eastern, and southern regions with higher elevations and larger slopes, in areas with inconvenient transportation, the development and construction of these areas were restricted by basic farmland protection areas; the unsuitable areas were concentrated in Changpuzi Miao and Dong township and Shuikou township in the middle, Lixiqiao town in the east and Zhaishi Miao and Dong township in the south, in high-altitude areas, this area was not suitable for development as construction land due to the comprehensive influence of natural and human factors.

\subsection{Accurate Identification of Potential Land Use Conflicts}

By constructing a multi-objective orientation evaluation model, a distribution map of the intensity of the land used orientation of villages, towns, agriculture, and ecological spaces in Suining county was obtained (Figure 4). Villages and towns in Suining county account for $43.29 \%, 53.76 \%$ and $2.95 \%$ of the total land area for villages and towns with low, medium and high tendencies, respectively; agricultural land with low, medium, and high tendencies occupies land respectively $87.48 \%, 10.43 \%, 2.08 \%$ of the total area; ecological land with low, medium, and high tendencies accounted for $24.25 \%, 39.25 \%$, and $36.27 \%$ of the total land area, respectively.

Using the land-use conflict recognition matrix, the results of potential land-use conflict recognition in Suining county are obtained (Figure 5 and Table 5). 

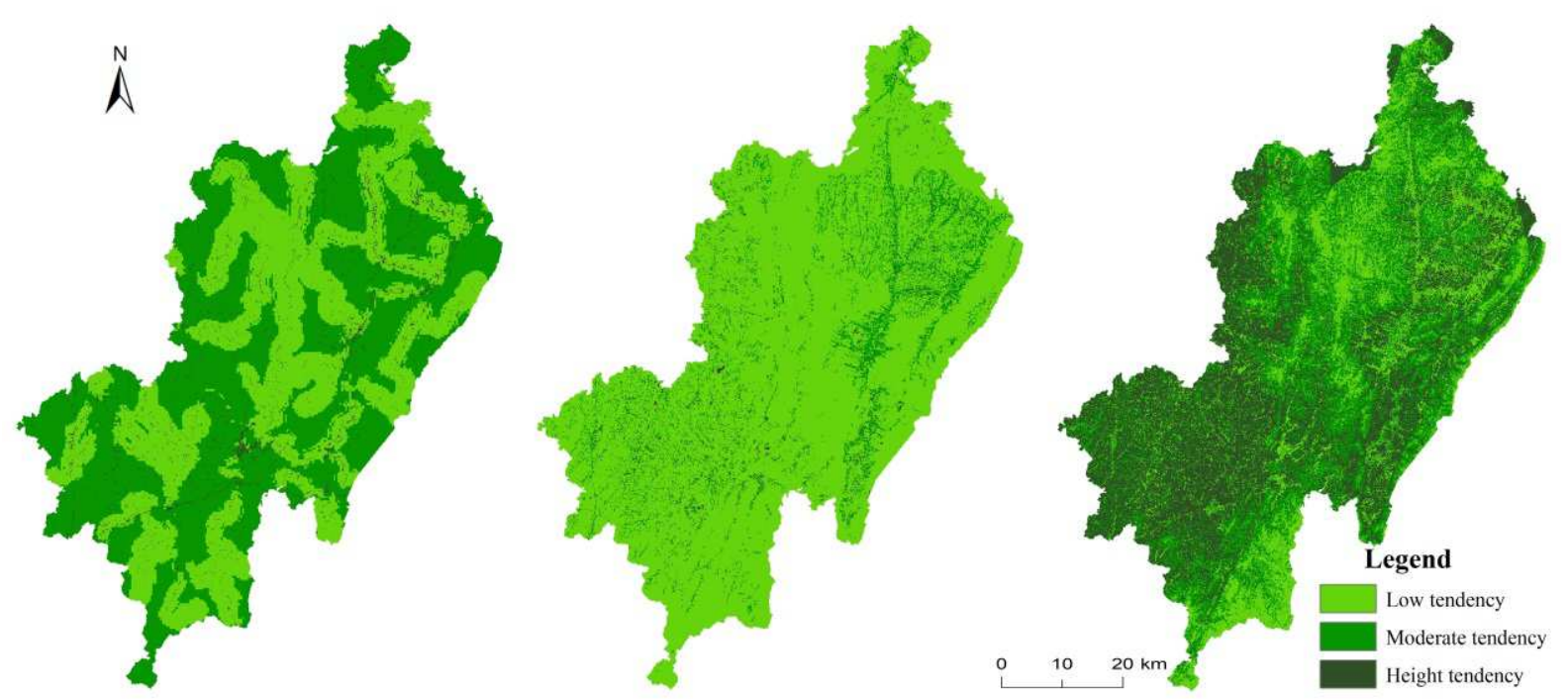

Figure 4. Distribution of construction land, agricultural land and ecological land use tendency.

Table 5. Statistical table of potential land use conflict types.

\begin{tabular}{lllllllll}
\hline Type area & Area $\left(\mathbf{k m}^{2}\right)$ & Proportion $(\%)$ & Type area & Area $\left(\mathbf{k m}^{2}\right)$ & Proportion $\mathbf{( \% )}$ & Type area & Area $\left(\mathbf{k m}^{2}\right)$ & Proportion $(\%)$ \\
\hline Y1 & 310.872 & 8.786 & J2 & 0.264 & 0.007 & B1 & 177.244 & 5.009 \\
Y2 & 1099.383 & 31.071 & J3 & 0.124 & 0.003 & B2 & 1464.067 & 41.378 \\
Y3 & 151.693 & 4.287 & Total J area & 0.388 & 0.010 & B3 & 55.363 & 1.565 \\
/ & $/$ & $/$ & W1 & 226.127 & 6.391 & B4 & 53.107 & 1.501 \\
Y area total & 1561.948 & 44.144 & Total W area & 226.127 & 6.391 & Total B area & 1749.781 & 49.453 \\
\hline
\end{tabular}

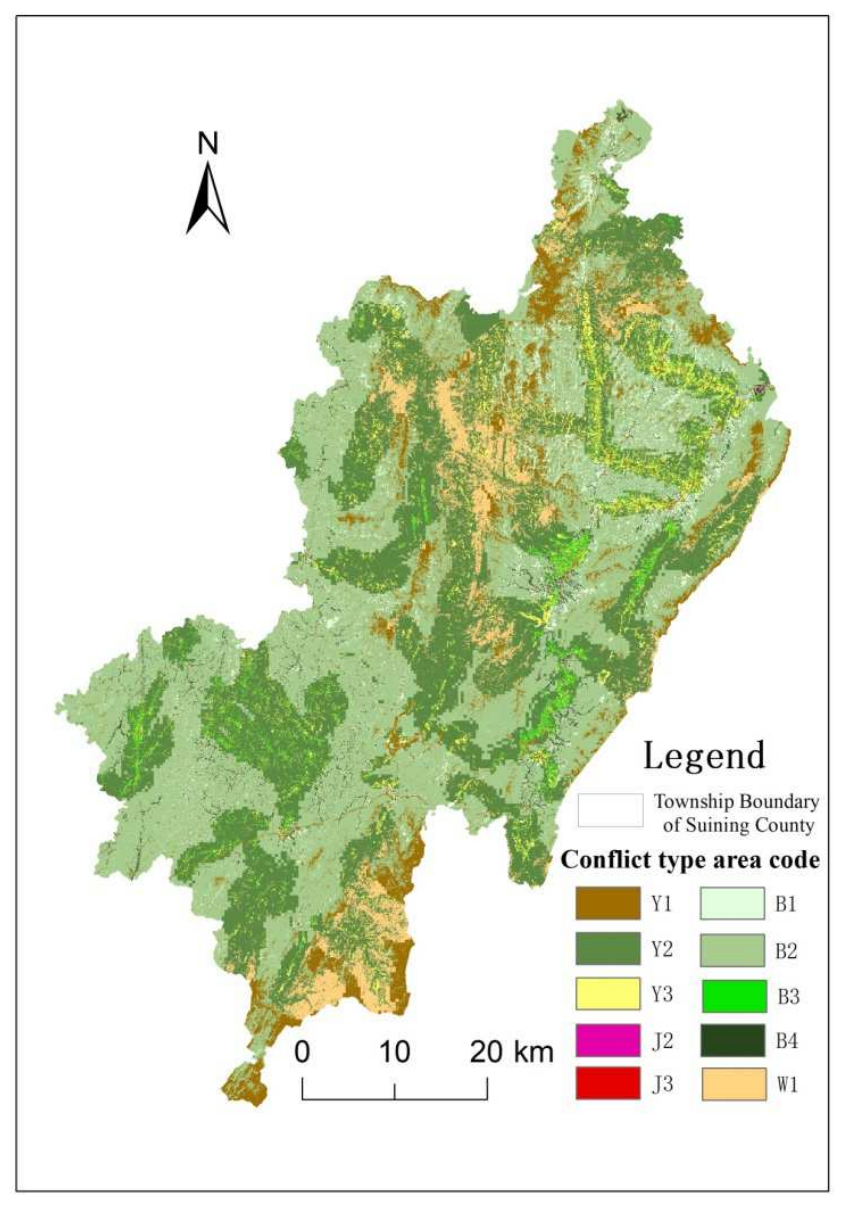

Figure 5. Identification of potential land use conflict identification results.
Suining county's land use advantage areas mainly included village and town land advantage area (Y1), agricultural land advantage area (Y2) and ecological land advantage area (Y3). Y1 was mainly distributed in Zhaishi Miao and Dong township in the south, and Shuikou township and Jinwutang town in the north; Y2 was mainly distributed in Tangjiafang town, Huangtukuang town, Hongyan town, etc. in the northeast, these areas were low in elevation, so it was suitable for agricultural production activities; Y3 area was relatively large, accounting for $31.071 \%$ of the total land area, and its distribution was relatively scattered, with obvious ecological advantages; The weak conflict zone (W1) was relatively concentrated, mainly in the junction of the three townships of Matang Miao and Yao townships, Shuikou township, Changpuzi Miao and Dong Townships in the north and Zhaishi Miao and Dong townships in the south. The county had obvious potential land use conflicts in the general conflict zone and the intense conflict zone, the general conflict zone was the largest, accounting for $49.45 \%$ of the total land area, and the conflict intense zone was the smallest, accounting for only $0.01 \%$. The general conflict zone includes the general conflict zone between villages and towns and agriculture (B1), the general conflict zone between villages and towns and ecology (B2), the general conflict zone between agriculture and ecology (B3) and the general conflict zone (B4). Among them, B2 had the largest area, accounting for $41.38 \%$ of the total land area, and its distribution was relatively scattered, and there was a certain risk of conflict with ecological land during the expansion of villages and towns; The area of B1 was the second, accounting for $5.10 \%$ of the total land area, 
mainly distributed in the northeast, due to the large area of agricultural advantage areas in these areas, there were a small amount of conflicts between rural land and agricultural land; the areas of B3 and B4 were relatively small, and the risk of land use conflicts was relatively small; The area of intense conflict between villages and towns, $\mathrm{J} 2$ and $\mathrm{J} 3$, where the conflict between ecology and agriculture was intense, small, and the risk of land use conflict was also the smallest.

\section{Conclusion}

This paper took Suining county, Shaoyang City, Hunan Province as an example, according to the actual situation of the study area, 12 evaluation indicators that affect the spatial expansion of villages and towns were selected, and the suitability of the spatial expansion of villages and towns in Suining county was evaluated; on this basis, the construction was calculated, Agricultural and ecological land, and then divided into three grades of high, middle and low using the natural breaking point method, listed the land use conflict identification matrix, and finally got the land use conflict identification results. The results showed that: Suining county had significant spatial differences in the suitability of spatial expansion of villages and towns, and the spatial distribution characteristics of different levels were quite different; the areas of the most suitable area, more suitable area, basic suitable area, less suitable area and unsuitable area for spatial expansion of villages and towns are respectively $183.6 \mathrm{~km}^{2}, 699.04 \mathrm{~km}^{2}, 1072.281 \mathrm{~km}^{2}$ $1006.79 \mathrm{~km}^{2}$ and $576.47 \mathrm{~km}^{2}$; the suitability of spatial expansion of each township was obviously different; the predominant land use areas of villages and towns were mainly distributed in Zhaishi Miao and Dong township and Changpu town in the south, and Shuikou township and Jinwutang in the north towns and other places; agricultural land predominant areas were mainly distributed in the northeast of Tangjiafang, Huangtukuang, Hongyan and other towns; ecological land predominant areas were relatively large and scattered; the types of areas with obvious potential land use conflicts were general conflict areas with intense conflicts, among which the general conflict zone was the largest, accounting for $49.45 \%$ of the total land area, and the intense conflict zone was the smallest, accounting for only $0.01 \%$; the villages and the agricultural conflict zone, the ecological and agricultural conflict zone, were all relatively small.

\section{Discussion}

Compared with urban spatial expansion, the expansion of villages and towns, especially the expansion of villages, was spontaneous and random to a certain extent due to the lack of unified planning and guidance by the government, and it did not comprehensively consider various factors such as nature, humanities and ecology. To some extent, the evaluation results were inconsistent with the actual expansion of villages and towns. In addition, due to the availability and length of data, this study failed to integrate multidisciplinary methods to explore the spatial justice and efficiency of land use conflicts in villages and towns under the background of rural revitalization strategies, and the coordination of land use conflicts under the integration of land and space planning systems at all levels. This will be also the direction of follow-up research.

\section{Fund}

This paper is supported by the National Key Research and Development Program of China named as "the Evaluation of the Suitability of the Spatial Expansion of Villages and Towns for County-Level" sub-topic 4 of "Key Technology of Space-Time Simulation for Spatial Expansion of Villages and Towns".

\section{References}

[1] Miller W, Collins W M G, Steiner F R, et al. An approach for greenway suitability analysis [J]. Landscape and Urban Planning, 1998, 42 (2/4): 91-105.

[2] Westman W E. Ecological Impact Assessment and Environmental Planning [M]. New York: John Wiley and Sons, 1985.

[3] Pham Duc Uy, Nobukazu Nakagoshi. Application of land suitability analysis and landscape ecology to urban green space planning in Hanoi, Vietnam [J]. Urban Forestry \& Urban Greening, 2008, 7 (1): 25-40.

[4] Yang Z S, Wang H, Zhang B S. Study on constructive land suitability evaluation in China's southwestern mountainous areas: A case in Mangshi, Yunnan province [C]. Research on Land Development \& Rearrangement and Building Urban and Industrial Projects on Mountainland in China, 2014.

[5] Xiao L, Li W, Feng C C, et al. Study on Land Rights and Interests Protection of Landless Farmers Based on the Stakeholder Theory [J]. Areal Research and Development, 2016, 35 (4): 131-136.

[6] Han H Q, Yang G B, Gao H J, et al. Evaluation on Suitability of Construction Land in Karst Area of Renhuai City [J]. Science of Surveying and Mapping, 2014, 39 (11): 76-79.

[7] Tan X, Yang X Q, Huang D Q, et al. Suitability Evaluation of Construction Land in Shenyang Metropolitan Area [J]. Journal of Beijing Normal University (Natural Science), 2017, 53 (5): 559-566.

[8] Cai C Y, Han N L, Mu X, et al. Suitability Assessment of Construction Lands in the New Area of Jiangdong, Haikou Based on GIS [J]. Journal of Subtropical Resources and Environment, 2020, 15 (2): 88-94.

[9] Yan H M. A Comparative Study on the Evaluation Methods of the Suitability of Land Resources Construction and Development—-Taking Fujian Province as an Example [J]. Southern Land and Resources, 2019, (5): 41-44.

[10] Jiang X L, Yang W. Suitability Evaluation of Urban Construction Land Exploitation Based on Production-Living-Ecology Space [J]. Jiangsu Agricultural Sciences, 2019, 47 (16): 282-285. 
[11] Hong B T, Ren P. Ecological Suitability Evaluation of Rural Residential Land Based on the Least Cumulative Resistance Model: A Case Study of Dujiangyan City [J]. Resources and Environment in the Yangtze Basin, 2019, 28 (6): 1386-1396.

[12] Qin T T, Qi W, Li Y Q, et al. Suitability Evaluation of Rural Residential Land Based on Niche Theory in mountainous area [J]. Acta Ecologica Sinica, 2012, 32 (16): 5175-5183.

[13] Xu F, Wang Z Q, Zhang H W, et al. Application of Random Forest Algorithm in Suitability Evaluation of Rural Residential Area [J]. Resources Science, 2018, 40 (10): 2085-2098.

[14] Tang S, Yu J, Chen Y H, et al. Suitability Evaluation of Rural Residential Land Under the background of Rural Revitalization: A Case Study of Cili County [J]. Journal of Hubei University (Natural Science), 2020, 42 (5): 531-538.

[15] Brown G, Raymond C M. Methods for identifying land use conflict potential using participatory mapping [J]. Landscape and Urban Planning, 2014, 122: 196-208.

[16] Pavón D, Ventura M, Ribas A, et al. Land use change and socio-environmental conflict in the Alt Empordà County (Catalonia, Spain) [J]. Journal of Arid Environments, 2003, 54 (3): 543-552.

[17] Iojă C I, Niţă M R, Vânău G O, et al. Using multi-criteria analysis for the identification of spatial land-use conflicts in the Bucharest Metropolitan Area [J]. Ecological Indicators, 2014, 42: 112-121.

[18] Adam Y O, Pretzsch J, Darr D. Land use conflicts in central Sudan: Perception and local coping mechanisms [J]. Land Use Policy, 2015, 42: 1-6.

[19] Delgado-Matas C, Mola-Yudego B, Gritten D, et al. Land use evolution and management under recurrent conflict conditions: Umbundu agroforestry system in the Angolan Highlands [J]. Land Use Policy, 2015, 42: 460-470.

[20] Tan S K. Research on Concept, Characters and Trigger Factors of Land Conflicts in China [J]. China Land Science, 2008, 22 (4): 4-11.
[21] Ruan S T, Wu K N. Research of the Land Use Conflict and Mitigation Mechanism During the Urbanization in China [J]. China Population, Resources and Environment, 2013, 23 (11): 388-392.

[22] Zhou D, Xu J C, Wang L. Progress of Land Use Conflict Research in China During the Past Fifteen Years $[\mathrm{J}]$. China Land Science, 2015, 29 (2): 21-29.

[23] Yu Z L, Zhang W X, Liang J S, et al. Research Progress on Suitability Evaluation of Territorial Space Development and Construction [J]. Progress in Geography, 2015, 34 (9): 1107-1122.

[24] Zeng M, Zhao Y L, Zhang X. Research on the Multi-purpose Suitability Evaluation Method of County Land from the Perspective of Urban: A Case of Jiahe County [J]. Journal of Hunan University of Science \& Technology (Natural Science Edition), 2014. 29 (1): 37-41.

[25] Lu X L. Land Suitability Evaluation Based on GIS [J]. Beijing Surveying and Mapping, 2015, (6): 13-17.

[26] Wang Y G, Yin X L, Li G C. Delimitation of Urban Growth Boundary Based on Land Ecological Suitability Evaluation: A Case of Shenshan Special Corporation Zone [J]. Urban Development Studies, 2012, 19 (11): 76-82.

[27] CARR M H, ZWICK P. Using GIS suitability analysis to identify potential future land use conflicts in North Central Florida. Journal of Conservation Planning, 2005, 1 (1): 89-105.

[28] Dai Y Q, Chen W Q, Gao H, et al. Research on the Identification of Rural Potential Land Use Conflicts Based on the Evaluation of Land Use Orientation: A Case Study of Dongping Village, Xixia County [J]. Resources and Environment in the Yangtze Basin, 2019, 28 (10): 2410-2418.

[29] Zhao X N, Gong X, Tian F H, et al. Evaluation of Ecological Suitability of Urban Land in Yanlongtu Region [J]. Journal of Natural Resources, 2017, 32 (05): 778-787. 